\title{
Effect of starter and finisher feed replacement time on the performance of broiler chickens
}

\section{A.B Thasleem and L.S David}

\author{
Department of Animal Science, Faculty of Agriculture, Eastern University, \\ Chenkalady, Sri Lanka, \\ alshiromi@yahoo.co.uk
}

\begin{abstract}
An experiment was conducted to find out the optimum time of broiler starter and finisher feed replacement on the growth performance, carcass quality and organ size of broiler chickens. The experiment was conducted at the Livestock farm of the Department of Animal Science, Faculty of Agriculture, Eastern University, Sri Lanka for a period of 42 days. A total of 120, unisex, Indian River strain, day-old broiler chicks were purchased and were allocated into four treatment groups with three replicates in a Complete Randomized Design, such as $T_{1}$ (Starter diet from 0 to 15 days and finisher diet from 16 to 42 days), $T_{2}$ (Starter diet from 0 to 18 days and finisher diet from 19 to 42 days), $T_{3}$ (Starter diet from 0 to 21 days and finisher diet from 22 to 42 days) and $T_{4}$ (Starter diet from 0 to 24 days and finisher diet from 25 to 42 days). The birds in the treatment $T_{2}$ recorded significantly highest body weight gain (2298 g) while the birds in the treatment $T_{3}$ recorded the lowest $(2030 \mathrm{~g})$. Increasing the starter diet period up to day 24 reduced the feed intake in the birds. The FCR of birds in treatment $T_{3}$ was significantly higher when compared to those in other treatments. The birds in treatment $T_{3}$ increased the dressing percentage in broiler chickens when compared to those of other treatments. The relative weights of gizzard, heart and liver were significantly lower in the birds of treatment $T_{4}$ when compared to others.
\end{abstract}

Keywords: Broiler chicken, body weight, carcass, finisher, starter.

\section{Introduction}

Broiler chicken meat is the most widely accepted meat in Sri Lanka. Unlike beef or pork, it does not have a religious taboo. Broiler chickens are gaining importance and account for a major share of animal products in human diets in many countries and broiler chicken meat and products are an important source of contribution to the gross domestic products and supporting livelihoods. Broiler chicken and their products are major component in agriculture in the developing countries and provide direct cash income for many farmers (Nordblom and Shomo, 2005). Broiler chicken meat production has increased rapidly in the last two decades in line with higher demand compared to other meat (Anon, 2014).

Feed represents over $70 \%$ of the cost of producing chicken meat (Agah and Norollahi, 2008). The cost of feed and other inputs for broiler chicken production keep on increasing while the prices of broiler meat and meat products do not increase by the same rate. It is therefore, important to use high quality feed that will increase the performance of the birds aimed at optimizing feed efficiency and therefore performance of the broiler chicken and profit on the farm. In addition, care should be taken to implement an efficient management practices to make profit from the broiler chicken industry. Profit oriented management decisions are directed towards increased income and reduced cost. Hence, this study was carried out to determine the effects of altering the starter and finisher dietary phases on growth performance of broilers.

\section{Location}

\section{Materials and methods}

This experiment was carried out in the Livestock farm of the Department of Animal Science, Eastern University, Sri Lanka. 


\section{Experimental design, birds and diets}

Total of one hundred and twenty, Indian River strain, unisex broiler day-old chicks were purchased from Prima (Pvt.) Ltd. in Sri Lanka and assigned into four dietary treatments in a complete randomized design. All treatments were divided into three replicates of ten chicks in each. The corn-soya based commercial broiler starter (2980 kcal/kg metabolizable energy and $21 \%$ crude protein) and broiler finisher $(3025 \mathrm{kcal} / \mathrm{kg}$ metabolizable energy and $18 \%$ crude protein) diets were used as the experimental diets.

\section{Dietary treatments}

After thirteen days of brooding period on an electrically heated floor brooder, each group was divided into three replicates of ten chicks in each. The dietary treatments were as follows:

T1 - Starter diet was given from 0 to 15 days and finisher diet from 16 to 42 days

T2 - Starter diet was given from 0 to 18 days and finisher diet from 19 to 42 days

T3 - Starter diet was given from 0 to 21 days and finisher diet from 22 to 42 days

T4 - Starter diet was given from 0 to 24 days and finisher diet from 25 to 42 days

The commercial broiler starter and finisher diets were offered in the forms of crumbles and pellets, respectively. Feed change was done gradually. The chicks were housed in floor pens. Clean and fresh water was provided all the time. The birds were vaccinated twice for Gumboro (Infectious Bursal Disease) on day 12 and day 16 and for Newcastle Disease on day 18.

\section{Measurement of performance parameters}

The average body weights and feed consumption were recorded on $7^{\text {th }}, 14^{\text {th }}, 21^{\text {st }}, 28^{\text {th }}, 35^{\text {th }}$ and $42^{\text {nd }}$ days during the experimental period. Body weight gains and feed conversion ratio (FCR) were then calculated using these measurements.

On day 42, the weights of organs such as heart, liver, empty gizzard and spleen were measured and the relative organ weights were calculated as a percentage of organ weight to the live weight of bird.
The birds were slaughtered on day 42 after withdrawal of feed for 12 hours before slaughtering. The live body weights and dressed weight of all birds were recorded. The dressing percentage was calculated as a percentage of dress weight to the live weight of bird.

Liveability of broiler chickens was estimated as a percentage of total number of birds sold to the total number of birds at beginning. The Broiler Performance Efficiency Factor (BPEF) was estimated as a percentage of live weight of birds to the feed conversion ratio. Broiler Farm Economy Index (BFEI) was calculated using the following formula:

BFEI $=\frac{\text { Average live weight }(\mathrm{kg}) \times \text { liveability }(\%)}{\text { Feed conversion ratio } x \text { Growing period }} \times 10$

\section{Statistical analysis}

All Data were analyzed by Analysis of Variance (ANOVA) using SAS 9.1 software package. Significant differences among treatment means were determined using Duncan's Multiple Range Test.

\section{Results and Discussion}

\section{Growth performance}

Table 2 shows the treatment effects on weight gain, feed intake and feed conversion ratio (FCR) of broiler chickens on day 42. The birds fed starter diet up to day $18\left(\mathrm{~T}_{2}\right)$ gained the highest body weight (P 0.05) while the birds fed starter diet up to day $21\left(\mathrm{~T}_{3}\right)$ gained the lowest. The feed intake was significantly higher in the birds fed starter diet up to day $15\left(\mathrm{~T}_{1}\right)$ and $21\left(\mathrm{~T}_{3}\right)$ while it was lowest in the birds fed starter diet up to day $24\left(\mathrm{~T}_{4}\right)$. The birds fed starter diet up to day $21\left(\mathrm{~T}_{3}\right)$ recorded the highest FCR $(\mathrm{P} \leq 0.05)$ than the birds in all other treatment groups where the FCR of birds in all other three groups were not significantly different. 
Table 2. Effect of feed replacement on the growth performance of broiler chicken on day 42 (Mean +SE)

\begin{tabular}{lllll}
\hline Parameter & \multicolumn{1}{c}{$\mathbf{T}_{1}$} & \multicolumn{1}{c}{$\mathbf{T}_{2}$} & \multicolumn{1}{c}{$\mathbf{T}_{3}$} & \multicolumn{1}{c}{$\mathbf{T}_{4}$} \\
\hline Body weight gain $(\mathrm{g})$ & $2213 \pm 46.3^{\mathrm{ab}}$ & $2298 \pm 87.7^{\mathrm{a}}$ & $2030 \pm 0.0^{\mathrm{b}}$ & $2200 \pm 45.1^{\mathrm{ab}}$ \\
Feed intake (g) & $3434 \pm 11.6^{\mathrm{a}}$ & $3416 \pm 3.9^{\mathrm{ab}}$ & $3431 \pm 8.8^{\mathrm{a}}$ & $3401 \pm 8.8^{\mathrm{b}}$ \\
FCR & $1.55 \pm 0.0^{\mathrm{b}}$ & $1.49 \pm 0.1^{\mathrm{b}}$ & $1.69 \pm 0.0^{\mathrm{a}}$ & $1.55 \pm 0.0^{\mathrm{b}}$ \\
\hline
\end{tabular}

a, b: Means having different letters within the same row are significantly different $(\mathrm{P}<0.05)$.

SE: Standard error of the mean $(n=3)$.

*: Treatments: Starter diet from 0-15 d and finisher diet from 16-42 d (T1), starter .diet from 0-18 d and finisher diet from 19-42 d (T2), starter diet from 0-21 d and finisher diet from 22-42 d (T3), starter diet from 0-24 $\mathrm{d}$ and finisher diet from 25-42 days (T4).

The highest body weight gain recorded in the birds of treatment $\mathrm{T}_{2}$ may be due to the efficient feed conversion ability in the birds in $\mathrm{T}_{2}$ when compared to that of other treatments. The reasons for increased body weight gain in the treatment $T_{4}$ when compared to that of $\mathrm{T}_{3}$ on day 42 may be due to long term feeding of starter mash than in other treatments. The high protein content of starter mash would have increased the body weight gain of birds in treatment $\mathrm{T}_{4}$. The chicks in all treatment groups other than $\mathrm{T}_{4}$ have received the high protein starter diet for a shorter period which could have increased the feed intake of those birds than that of $\mathrm{T}_{4}$. These results agree with Kamran et al. (2008) that feed intake is linearly increased with reduced crude protein during grower, finisher and overall periods. The increased feed intake is probably due to greater energy requirements of the broiler birds to cope with the high growth rate which is achieved by high intake in low energy diets.

The current results contradict with findings of Saleh et al. (1997), who reported no significant difference in the feed intake of broilers when feeding the starter diet up to 7,14 and 21 days of age. In addition, the environment was not controlled, which meant that birds were partially exposed to fluctuating external conditions that have a direct impact on feed consumption. Feed intake is a critical factor determining broilers performance especially body weight gain with the compensatory growth (Lilburn, 1998).

The highest FCR $(\mathrm{P} \leq 0.05)$ recorded in the birds fed starter diet up to day $21\left(\mathrm{~T}_{3}\right)$ may be due to the lowest body weight gain reported in the birds of treatment $\mathrm{T}_{3}$ when compared to others. Gajana et al. (2011) reported significantly highest FCR in the birds fed starter diet up to day 18 when compared to those fed up to day 15 and 21 during the third week of the experiment. However, during the fifth week, significantly lowest FCR was observed in the birds fed starter diet up to day 21 followed by those fed up to day 15 and 18 .

\section{Organ size}

Table 3 shows the treatment effects on the relative organ weights of broiler chickens on day 42. Significant differences were recorded on the relative weights of gizzard, heart and liver of the broiler chickens. Significantly highest relative gizzard weight was recorded in the birds fed starter diet up to day $21\left(\mathrm{~T}_{3}\right)$ while it was lowest in those fed up to day $24\left(\mathrm{~T}_{4}\right)$. Similarly, the lowest relative heart and liver weights were recorded in the birds fed starter diet up to day $24\left(\mathrm{~T}_{4}\right)$ when compared to those of other treatments where there was no significant difference among $\mathrm{T}_{1}, \mathrm{~T}_{2}$ and $\mathrm{T}_{3}$. After day 21, the high protein starter diet might contribute to the muscle development rather than the organ development which could have reduced the relative gizzard, heart and liver weights in the birds of $\mathrm{T}_{4}$. Adesehinum et al. (2005) suggested that increased relative heart weight was due to difference in nutrient intake and its utilization which closely related to the rate of organ weight. 
Table 3. Effect of feed replacement time on the organ weight ( $\mathrm{g} / 100 \mathrm{~g}$ body weight) of broiler chickens on day 42 (Mean+ SE).

\begin{tabular}{lcccc}
\hline $\begin{array}{l}\text { Relative organ weight }(\mathbf{g} / \mathbf{1 0 0 g} \text { body } \\
\text { weight) }\end{array}$ & $\mathbf{T}_{\mathbf{1}}$ & $\mathbf{T}_{\mathbf{2}}$ & $\mathbf{T}_{\mathbf{3}}$ & $\mathbf{T}_{\mathbf{4}}$ \\
\hline Gizzard & $2.13 \pm 0.0^{\mathrm{b}}$ & $2.18 \pm 0.0^{\mathrm{b}}$ & $2.38 \pm 0.1^{\mathrm{a}}$ & $1.61 \pm 0.1^{\mathrm{c}}$ \\
Heart & $3.94 \pm 0.1^{\mathrm{a}}$ & $3.80 \pm 0.1^{\mathrm{a}}$ & $3.85 \pm 0.2^{\mathrm{a}}$ & $3.02 \pm 0.1^{\mathrm{b}}$ \\
Liver & $1.65 \pm 0.0^{\mathrm{a}}$ & $1.48 \pm 0.1^{\mathrm{a}}$ & $1.56 \pm 0.1^{\mathrm{a}}$ & $0.89 \pm 0.0^{\mathrm{b}}$ \\
Spleen & $1.01 \pm 0.1$ & $1.00 \pm 0.1$ & $0.96 \pm 0.1$ & $0.95 \pm 0.1$ \\
\hline
\end{tabular}

$a, b, c$ : Means having different letters within the same row are significantly different $(\mathrm{P}<0.05)$.

SE: Standard error of the mean $(n=3)$.

*: Treatments: Starter diet from 0-15 d and finisher diet from 16-42 d (T1), starter .diet from 0-18 d and finisher diet from 19-42 d (T2), starter diet from 0-21 d and finisher diet from 22-42 d (T3), starter diet from 0-24 $\mathrm{d}$ and finisher diet from 25-42 days (T4).

\section{Carcass characteristics}

Table 4 shows the treatment effects on the carcass characteristics of broiler chickens. Significant differences were recorded for the live weight and dressing percentage of broiler chickens. Live weights of birds fed starter diet up to day $18\left(\mathrm{~T}_{2}\right)$ and day $24\left(\mathrm{~T}_{4}\right)$ were significantly highest while it was lowest in those fed starter diet up to day $21\left(\mathrm{~T}_{3}\right)$. This could be due to the higher body weight gains recorded in the birds fed starter diet up to days $18\left(\mathrm{~T}_{2}\right)$ and $24\left(\mathrm{~T}_{4}\right)$ when compared to that of $\mathrm{T}_{3}$. Dressing percentage was highest in the birds fed with starter diet up to day $21\left(\mathrm{~T}_{3}\right)$ while it was lowest in those fed up to day $15\left(T_{1}\right)$. Increasing the duration of feeding starter diet increased the dressing percentage up to day 21 . The lowest dressing percentage recorded in the birds fed starter diet up to day $15\left(\mathrm{~T}_{1}\right)$ could be due to the short time feeding of starter diet when compared to others. However, Saleh et al. (1997) reported that no significant difference among the dressing percentage of broiler chickens when fed starter diet up to days 7,14 and 21 .

Table 4. Effect of feed replacement time on the carcass characteristics of broiler chicken on day 42 (Mean+ SE)

\begin{tabular}{lllll}
\hline Parameter & \multicolumn{1}{c}{$\mathbf{T}_{1}$} & \multicolumn{1}{c}{$\mathbf{T}_{2}$} & \multicolumn{1}{c}{$\mathbf{T}_{3}$} & \multicolumn{1}{c}{$\mathbf{T}_{4}$} \\
\hline Live weight $(\mathrm{g})$ & $2287 \pm 46.7^{\mathrm{ab}}$ & $2393 \pm 78.1^{\mathrm{a}}$ & $2100 \pm 57.7^{\mathrm{b}}$ & $2316 \pm 60.1^{\mathrm{a}}$ \\
Carcass weight $(\mathrm{g})$ & $1567 \pm 88.2$ & $1667 \pm 66.7$ & $1583 \pm 44.1$ & $1583 \pm 16.7$ \\
Dressing percentage (\%) & $68.40 \pm 3.5^{\mathrm{b}}$ & $69.73 \pm 2.2^{\mathrm{ab}}$ & $75.43 \pm 2.4^{\mathrm{a}}$ & $68.47 \pm 3.0^{\mathrm{ab}}$ \\
\hline
\end{tabular}

a, b: Means having different letters within the same row are significantly different $(\mathrm{P}<0.05)$.

SE: Standard error of the mean $(n=3)$.

*: Treatments: Starter diet from 0-15 d and finisher diet from 16-42 d (T1), starter .diet from 0-18 d and finisher diet from 19-42 d (T2), starter diet from 0-21 d and finisher diet from 22-42 d (T3), starter diet from 0-24 $\mathrm{d}$ and finisher diet from 25-42 days (T4).

\section{Liveability, Performance Efficiency Factor (BPEF) and Farm Economy Index (BFEI)}

Tables 5 shows the treatment effect on Liveability, Broiler Performance Efficiency Factor (BPEF) and Broiler Farm Economy Index (BFEI). Significant difference was recorded for the broiler performance efficiency factor in which the birds fed starter diet up to day $18\left(\mathrm{~T}_{2}\right)$ recorded the highest performance while those fed up to day $21\left(\mathrm{~T}_{3}\right)$ recorded the lowest. However, the values recorded for all treatment groups indicated the better performance of the birds. A BPEF value of 100 or more is desirable (Anon, 2010). 
Table 5. Effect of feed replacement time on liveability, Broiler Performance Efficiency Factor (BPEF) and Broiler Farm Economy Index (BFEI) of broiler chickens on day 42 (Mean+ SE).

\begin{tabular}{lllll}
\hline Parameter & \multicolumn{1}{c}{$\mathbf{T}_{1}$} & \multicolumn{1}{c}{$\mathbf{T}_{\mathbf{2}}$} & \multicolumn{1}{c}{$\mathbf{T}_{\mathbf{3}}$} & \multicolumn{1}{c}{$\mathbf{T}_{4}$} \\
\hline Liveability $(\%)$ & $86.67 \pm 13.3$ & $70.00 \pm 17.3$ & $93.33 \pm 3.3$ & $96.67 \pm 3.3$ \\
BPEF & $147.26 \pm 0.1^{\mathrm{ab}}$ & $159.83 \pm 1.7^{\mathrm{a}}$ & $124.26 \pm 0.0^{\mathrm{b}}$ & $146.95 \pm 0.1^{\mathrm{ab}}$ \\
BFEI & $3.73 \pm 0.5$ & $2.32 \pm 0.6$ & $2.97 \pm 0.1$ & $3.77 \pm 0.2$ \\
\hline
\end{tabular}

a,b: Means having different letters within the same row are significantly different $(\mathrm{P}<0.05)$,SE: Standard error of the mean $(\mathrm{n}=3)$. *: Treatments: Starter diet from 0-15 d and finisher diet from 16-42 d (T1), starter .diet from 0-18 d and finisher diet from 19-42 d (T2), starter diet from 0-21 d and finisher diet from 22-42 $\mathrm{d}$ (T3), starter diet from 0-24 d and finisher diet from 25-42 days (T4).

There were no significant differences recorded among the treatments for the BFEI and liveability. In addition, the BFEI values recorded for all treatment groups indicated the optimum performance of the birds. A BFEI value of 2.0 and above indicates better management of the farm and optimal performance of the birds whereas a value less than 1.3 indicates poor performance of the flock (Anon, 2010).

\section{Conclusion}

Even though the birds fed starter diet up to day 21 showed higher dressing percentage than those fed up to day 18 , which was not significant based on the current study, the birds fed starter diet up to day 18 gained significantly higher body weight than those fed up to day 21. Therefore, it could be concluded that feeding starter diet up to day 18 significantly increases the body weight gain in broiler chickens than those fed up to day 15,21 and 24.

\section{References}

Anonymous (2014). Good times ahead for poultry sector. Development.lk, Ministry of mass media. http://www.development.lk/ news_details-7-1203.html. Accessed 28-092015.

Anonymous (2010). Broiler management. Expert system for poultry. Tamil Nadu Agricultural University.http://agritech.tnau.ac.in/ expert_system/poultry/Broiler\%20 Management.html. Accessed 28-09-2015.

Agah, M.J. and H. Norollahi (2008). Effect of feed form and duration time in growing period on broilers performance. International Journal of Poultry Science, 7(11): 1074-1077.
Adesehinum, D.F. and Micheal, P.L. (2005). Commercial Broiler production, pp 145-152.

Gajana, C. S., T.T. Nkukwana., M. Chimonyo and V. Muchenje (2011). African Journal of Biotechnology, 10(64): 14203-14208.

Kamran, Z., M. Sarwar., M. Nisa., M.A. Nadeem., S. Mahmood., M.E. Babar and S. Ahmed (2008). Effect of low-protein diets having constant energy-to-protein ratio on performance and carcass characteristics of broiler chickens from one to thirty five days of age. Poultry Science, 87: 468-474.

Liburn, M. S. (1998). Practical aspects of early nutrition for poultry. Journal of Applied Poultry Research, 7: 420-424.

Nordblom, T. L. and Shomo, F. (2005). Food and feed Prospects to 2020 in the west AsiaNorth Africa Region. Social Science Paper No.02.International Centre for Agricultural Research in the Dry Areas (ICARDA), Alepro, Syria.

Saleh, E. A., S.E. Watkins and P.W. Waldroup (1996). Effect of changing time of feeding starter, grower and finisher diets on broiler performance. 1. Birds grown to $1 \mathrm{~kg}$. Journal of Applied Research, 5(3): 269 275.

Saleh, E. A., S.E. Watkins and P.W. Waldroup (1997). Changing time on feeding starter, grower and finisher diets for broilers 3. Birds grown to $3.3 \mathrm{~kg}$. Journal of Applied Research, 6(3):290-297. 